\title{
Study on Genetic Variance of miR-541 in Type 1 Diabetes
}

\author{
Bei Han, ${ }^{1}$ Xing Shi, ${ }^{1}$ Quan Peng, ${ }^{2}$ and Wentao Gao ${ }^{2}$ \\ ${ }^{1}$ Department of Endocrinology, Nanjing Children's Hospital Affiliated to Nanjing Medical University, Nanjing 210029, China \\ ${ }^{2}$ Division of Biliary and Pancreatic Disease, Department of General Surgery, The 1st Affiliated Hospital of Nanjing \\ Medical University, No. 300 Guangzhou Road, Nanjing 210029, China
}

Correspondence should be addressed to Wentao Gao, gao11@hotmail.com

Received 8 October 2012; Accepted 25 October 2012

Academic Editors: K. Yamagami and K. Zajickova

Copyright (C 2012 Bei Han et al. This is an open access article distributed under the Creative Commons Attribution License, which permits unrestricted use, distribution, and reproduction in any medium, provided the original work is properly cited.

Genetic susceptibility plays a key role in type 1 diabetes development. Because miR-541 gene was located within the associated chromosome loci and its target genes include the diabetes-associated gene neurogenin3, this study aimed to investigate whether miR-541 had type 1 diabetes-associated genetic variations. Type 1 diabetes children and healthy volunteers were recruited; direct sequencing was performed in initial 69 patients and 46 volunteers. We identified 1 reported SNP (rs12893725) and 3 novel genetic variations, for the candidate $-404 \mathrm{G} \rightarrow \mathrm{T}$ variation, restriction fragment length polymorphism (RFLP) was performed in total 247 diabetes children and 212 healthy volunteers, a different distribution trait of allele frequencies was found between the two groups, and further clinical analysis found no significant correlation between clinical parameter and genotypes among patients. In addition, by luciferase reporter assay, -404 was found to be within putative promoter region of pre-miR-541; although mutation of $\mathrm{G} \rightarrow \mathrm{T}$ has no effect on promoter activity, a significant secondary structure alteration may possibly influence its processing and transcription. In conclusion, we identified 3 novel genetic variations in putative promoter of miR-541 in type 1 diabetes patients; $-404 \mathrm{G} \rightarrow \mathrm{T}$ of $\mathrm{miR}-541$ is a potential T1D-associated genetic variation.

\section{Introduction}

Patients with type 1 diabetes are likely to carry strong genetic predispositions [1,2]. A group of insulin-dependent diabetes mellitus (IDDM) susceptibility loci, including 19 IDDM loci on human chromosomes, have been identified [3].

MicroRNAs (miRNAs) play an important role in the posttranscriptional regulation mechanism in eukaryotic cells [4]. It has been reported that miRNAs are associated with the development of pancreatic $\beta$ cells, production and secretion of insulin, and insulin action on target organs, such as adipose tissue, liver, and skeletal muscle [5-10] and, more importantly, in immune regulation and autoimmune diseases [11], it can be speculated that miRNAs might affect the development of type 1 diabetes which was characterized as autoimmune insulitis with genetic susceptibility. Indeed, a miRNA expression profile has been reported for type 1 diabetes cell model recently [12].

Several reports on the genetic variations, single nucleotide polymorphisms (SNPs), and mutations in miRNAs have been reported in genetic diseases and tumor somatic and germ cells $[13,14]$, which can lead to dysfunctional regulation of miRNAs $[15,16]$. Bioinformatic analysis has led to the identification of many miRNAs in the IDDM region of the type 1 diabetes-susceptible chromosome [17]; miR541 is located at $14 q 32$ in the IDDM16 region and plays a crucial role in the development of pancreas [18]. Its target genes include diabetes-related gene neurogenin3 (NGN3) [19]. The present study focuses on the genetic variants of the miRNA miR-541 to investigate its association with type 1 diabetes.

\section{Materials and Methods}

2.1. Patient Group. Total 247 children diagnosed with type 1 diabetes between January 2006 and April 2012 at the Department of Endocrinology, Nanjing Medical University Associated Nanjing Children Hospital were selected. Initially, 69 children were selected for sequencing to screen; then all patients were included for secondary restriction fragment length polymorphism (RFLP) study for identified genetic variance. Sequencing group includes 36 females and 
33 males, with an average age of $11.02 \pm 2.48$ years; RFLP group includes 119 females and 128 males, with average age of $7.52 \pm 4.06$ years. The diagnosis was made on the basis of the criteria approved by the Chinese Diabetes Association in 1999.

Total 212 healthy volunteers were selected as controls, including 118 female and 94 male, with an average age of $9.21 \pm 4.32$ years; the initial 46 controls for sequencing include 24 females and 22 males (average age, $11.12 \pm 2.59$ years). All patients and volunteers provided written informed consent, and the study protocol was approved by ethics committee of Nanjing Children Hospital.

Peripheral anticoagulant plasma was collected. Ultrapure Genomic DNA Fast-Extraction kit was used to extract DNA that was stored at $-20^{\circ} \mathrm{C}$ until further use.

\subsection{Study Area and Polymerase Chain Reaction Amplification} of Pre-miR-541. 2 overlapping primers were designed, with an amplification area in the -1084 to +167 bp region of the pre-miR-541, so that its promoter (regulation) region and pre-miRNA were also included. The sequence of the primers used is shown in Table 1 . Polymerase chain reaction (PCR) protocol was used as follows: denaturation at $95^{\circ} \mathrm{C}$ for $5 \mathrm{~min}$, elongation at $55^{\circ} \mathrm{C}, 35$ cycles, followed by $72^{\circ} \mathrm{C}$ for $5 \mathrm{~min}$. GoTaq DNA polymerase used for PCR amplification was purchased from Promega Corporation.

2.3. DNA Sequencing. ABI3730 sequencer (Gene Company) was used for sequencing analysis. Both forward and reverse sequencing reactions were performed.

2.4. PCR-Restriction Fragment Length Polymorphism (RFLP). For the variation point $-404 \mathrm{G} \rightarrow \mathrm{T}$ identified by direct sequencing, RFLP analysis was performed using $-404 \mathrm{G} \rightarrow \mathrm{T}$ specific restriction enzyme DpnII.

2.5. Luciferase Reporter Gene Assay. Design primers containing restriction enzyme sites EcoRI and HindIII, MiR541_P_EcoRI-F: CG-GAATTC-GCGTTTCTCATGAGCCTTTC, MiR541_P_HindIII-R: TCCG-AAGCTT-CAACC TTCCC CAGAC TCAGA, the amplified fragment is from $-780 \mathrm{bp} \sim+167$ of the pre-miR-541, wild type and -404 $\mathrm{G} \rightarrow \mathrm{T}$ mutated fragments were constructed into PGL3 BASIC, respectively. Validate these plasmids through sequen-cing in INVITROGEN. Set PRL as internal control. Collect the lysates after $48 \mathrm{~h}$ and measure fluorescence (integration: $10 \mathrm{~s}$ ).

The influence of genetic mutation on the secondary structure of miR-541 precursor RNAfold web server was used to predict the secondary structure of the wildtype and $-404 \mathrm{G} \rightarrow \mathrm{T}$ mutated miR-541.

2.6. Data Analysis. Comparisons of genotype frequencies between the groups were conducted using a chi-square test; comparisons of clinical parameter were conducted using Student's $t$-test (SAS software). A $P$ value of $<0.05$ was considered significant.

\section{Results}

3.1. A Known SNP (Reported in the SNP Database) and 3 Novel Genetic Mutations Were Identified by DNA Sequencing. Sequencing study includes 69 T1D patients and 46 controls. By direct sequencing, 1 reported single nucleotide polymorphism (SNP) (rs12893725) (in SNP database) and 3 unreported gene mutations were identified, including heterozygote $-284 \mathrm{C} \rightarrow \mathrm{T}$, heterozygote $569 \mathrm{G} \rightarrow \mathrm{A}$ and heterozygote $-404 \mathrm{G} \rightarrow \mathrm{T}$ (Figure 1 ).

The -635 homozygote and heterozygote variant rs12893725 reported in the SNP database were detect with high frequency in the type 1 diabetes (27/69 and $12 / 69$ ) and normal children (16/46 and 4/46); no significant difference was observed between the diabetes and normal children. Newly identified heterozygote polymorphisms -284 $\mathrm{C} \rightarrow \mathrm{T}$ were observed in both patients $(11 / 69)$ and controls (5/46), with no statistical difference. Newly identified heterozygote polymorphisms $-569 \mathrm{G} \rightarrow$ A were also observed in both patients (11/69) and controls (7/46), with no statistical difference (Table 2).

Heterozygote $-404 \mathrm{G} \rightarrow \mathrm{T}$ was observed in only 3 diabetic patients but not in the first group of 46 controls, with statistical significance.

3.2. RFLP Analysis of miR-541 -404 G $\rightarrow$ T Reveals a Different Distribution of Allele Frequencies between Type 1 Diabetes Patients and Healthy Volunteers. RFLP screening was performed for the heterotype $-404 \mathrm{G} \rightarrow \mathrm{T}$ mutation using specific DpnII restriction enzyme in 247 type 1 diabetes patients and 212 healthy volunteers. Primer 2 that was $992 \mathrm{bp}$ long was used for the RFLP analysis. $-404 \mathrm{G} \rightarrow \mathrm{T}$ polymorphism was observed in 9/247 patients and 4/212 healthy volunteers by RFLP, indicating that it was a rare SNP (Figure 2).

The genotype frequencies of GG, GT, and TT were $96.36 \%, 3.24 \%$, and $0.40 \%$ in type 1 diabetes patients and $98.11 \%, 1.89 \%$ and $0 \%$ in healthy volunteers, respectively. The frequencies of $\mathrm{G}$ and $\mathrm{T}$ allele were $97.98 \%$ and $2.02 \%$ in type 1 diabetes patients and $99.06 \%$ and $0.94 \%$ in healthy volunteers (Table 3 ); the allele frequencies are significantly different between diabetes patients and healthy controls.

\subsection{No Significant Correlation between Clinical Parameter and Genotype of miR-541 -404 $G \rightarrow T$ in Type 1 Diabetes Children. Clinical parameters of type 1 diabetes children are analyzed, including sex, age, weight, $C$ peptide $(0 \mathrm{~min}$ and $120 \mathrm{~min}$ ), HbAC (glycosylated hemoglobin), and ketoacido- sis (Table 4). Compared to wildtype GG, there was no signif- icant difference for genotype GTs in all clinical parameters, although GT have a tendency of lower serum $C$ peptide, but all $P$ values $>0.05$.}

3.4. Luciferase Reporter Gene Assay Shows -780 bp +167 Region of miR-541 Containing Promoter Activity; However miR-541 -404 G $\rightarrow$ T Had No Significant Influence on Promoter Activity. From $-780 \mathrm{bp} \sim+167$ of the pre-miR541, wildtype and $-404 \mathrm{G} \rightarrow \mathrm{T}$ mutated fragments were 
TABLe 1: Primers for mir-541 and replication region.

\begin{tabular}{lcc}
\hline & Primer 1 & Primer 2 \\
\hline Replication region & $-780 \sim+167$ & $-1084 \sim-112$ \\
Replication length & $947 \mathrm{bp}$ & $992 \mathrm{bp}$ \\
$5^{\prime}$ primer & GCGTTTCTCATGAG & TCAGTGGGGTCTGGTCTTTC \\
$3^{\prime}$ primer & CAACCTTCCCCAGA & CAGACGACTTCCCTTCAGG \\
\hline
\end{tabular}

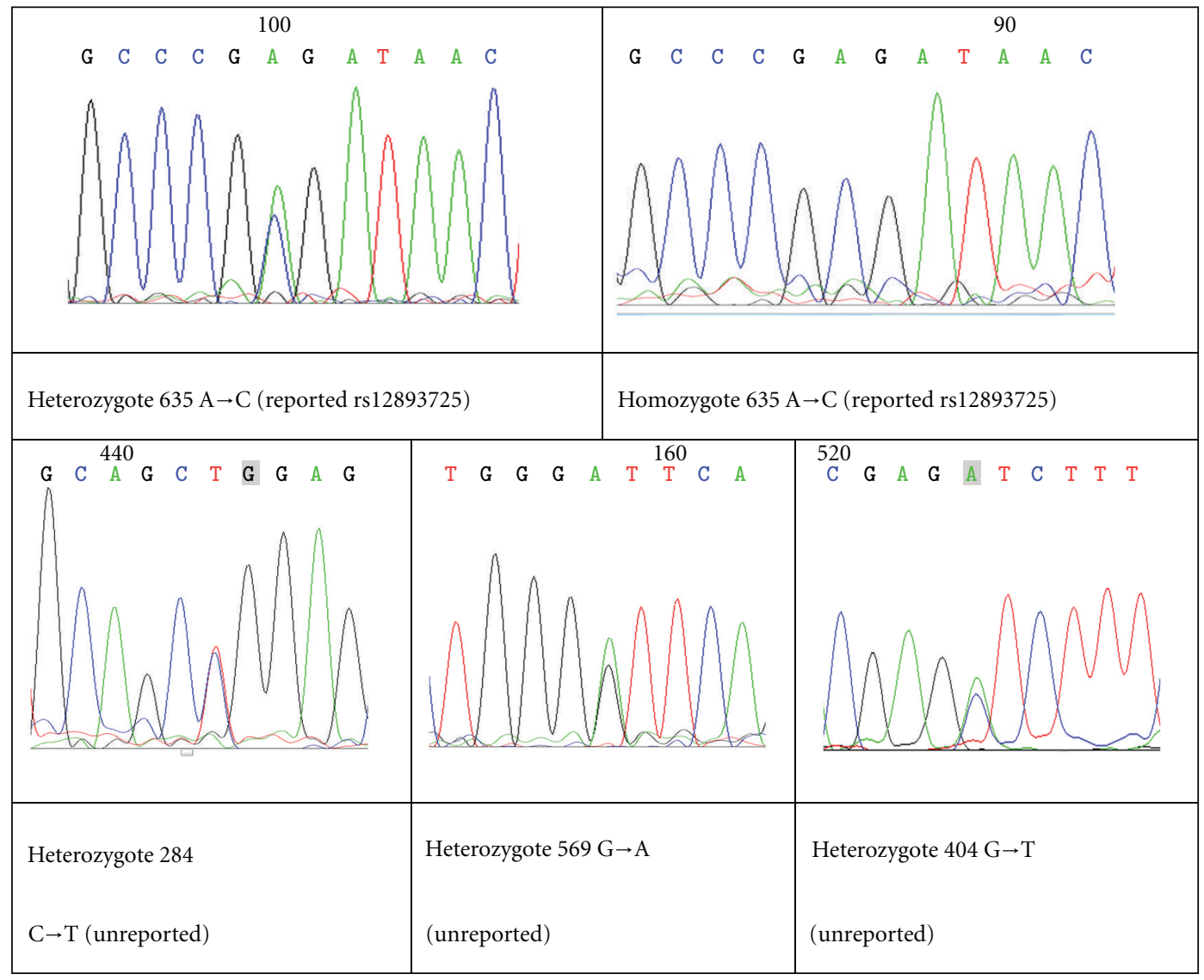

FIGURE 1: A known SNP and 3 novel genetic mutations were identified by DNA sequencing. In this study, 1 reported single nucleotide polymorphism (SNP) (rs12893725) (in SNP database) and 3 unreported gene mutations were identified by sequencing. Heterozygote -284 $\mathrm{C} \rightarrow \mathrm{T}$ and heterozygote $-569 \mathrm{G} \rightarrow$ A were newly identified SNPs. Heterozygote $-404 \mathrm{G} \rightarrow \mathrm{T}$ was observed in only 3 diabetic patients.

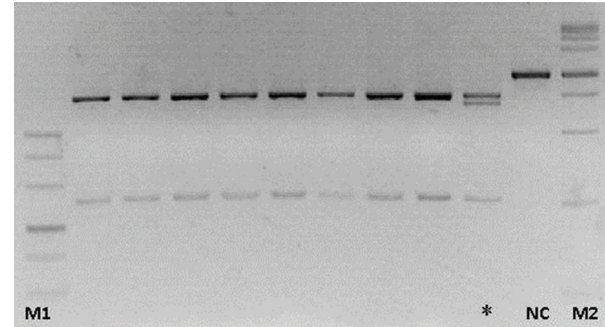

(a)

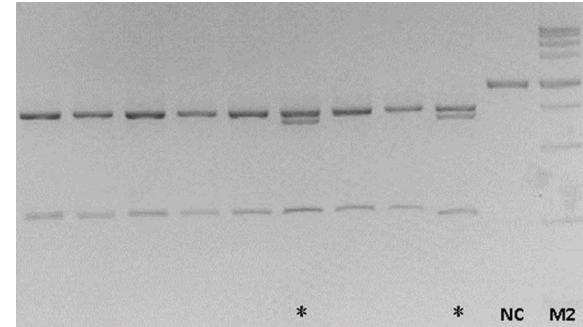

(b)

FIgURE 2: Restriction fragment length polymorphism (RFLP) analysis for $-404 \mathrm{G} \rightarrow \mathrm{T}$. Polymerase chain reaction (PCR) amplification length was $992 \mathrm{bp}$. Nonmutated amplification region includes 1 DpnII site, generating $741+251$ digested fragments. However, for heterozygote $-404 \mathrm{G} \rightarrow$ T mutation, another DpnII site (GAGC $\rightarrow$ GATC) is present, thereby generating 4 digested fragments $741+680+251+61$ (the $61 \mathrm{bp}$ fragment was extremely small and hence could not be visualized). NC is the negative control (without enzymatic digestion), M1 and M2 for marker, * for samples with heterozygote $-404 \mathrm{G} \rightarrow \mathrm{T}$ mutation. 
TABLE 2: Comparison of mir-541 genetic variation identified by direct sequencing between type 1 diabetes children and control groups.

\begin{tabular}{lcc}
\hline & $\begin{array}{c}\text { Type 1 diabetes } \\
\text { patients } \\
n=69\end{array}$ & $\begin{array}{c}\text { Healthy controls } \\
n=46\end{array}$ \\
\hline $\begin{array}{l}\text { Homozygote variant -635 } \\
\text { rs12893725 }\end{array}$ & $27(39.13 \%)$ & $16(34.78 \%)$ \\
$\begin{array}{l}\text { Heterozygote variant -635 } \\
\text { rs12893725 }\end{array}$ & $12(17.39 \%)$ & $4(8.70 \%)$ \\
$\begin{array}{l}\text { Heterozygote -284 C } \rightarrow \mathrm{T} \\
\text { Heterozygote }-569 \mathrm{G} \rightarrow \mathrm{A}\end{array}$ & $11(15.94 \%)$ & $5(10.87 \%)$ \\
Heterozygote -404 G $\rightarrow \mathrm{T}$ & $3(15.35 \%) *$ & $7(15.22 \%)$ \\
${ }^{*}$ Comparison with control group, $P$ value $<0.05$. & 0
\end{tabular}

constructed into PGL3 BASIC, respectively. In contrast to PGL3 BASIC control vector, the constructed plasmid containing $-780 \mathrm{bp} \sim+167$ regions had promoter activity, indicating a putative promoter of miR-541 in this region.

However, there is no significant difference in promoter activity between wildtype and $-404 \mathrm{G} \rightarrow \mathrm{T}$ mutation construct (Figure 3).

3.5. Mutation in $-404 G \rightarrow T$ Altered the Secondary Structure of miR-541 Precursor, which May Influence the miR-541 Processing and Maturation. It is essential that the miRNA precursors have an appropriate secondary structure and ciselement during the precursor processing and maturation stages. In our study, although most of the mutations did not cause significant alterations in the secondary structure of miRNAs, the $-404 \mathrm{G} \rightarrow \mathrm{T}$ mutation altered the secondary structure of pre-miR-541 at the ring-shaped region, which is adjacent to the root ring structure of pre-miR-541, which may influence the miR-541 processing and maturation (Figure 4).

\section{Discussion}

This study found one reported SNP and 3 unreported SNPs for the first time. Among them, $-404 \mathrm{G} \rightarrow \mathrm{T}$ was found to be a rare SNP; a different distribution trait of allele frequencies of $-404 \mathrm{G} \rightarrow \mathrm{T}$ was found between type 1 diabetes patients and healthy volunteers, -404 located within promoter of premiR-541; although $\mathrm{G} \rightarrow \mathrm{T}$ has no effects on promoter activity, it leads to a significant secondary structure alteration of premiR-541, which may possibly influence its processing and maturation.

Newly identified heterozygote $-404 \mathrm{G} \rightarrow \mathrm{T}$ was a rare SNP associated with type 1 diabetes; a different distribution trait of allele frequencies of $-404 \mathrm{G} \rightarrow \mathrm{T}$ was found between type 1 diabetes patients and healthy volunteers. By comparison of biochemical characterization and clinical parameters between different -404 alleles among patients, we found a lower c-peptide value (both 0 and $120 \mathrm{~min}$ ) in $\mathrm{T}$ allele compared with wildtype $\mathrm{G}$ allele; however no statistic significance was found. Since it is a rare SNP and

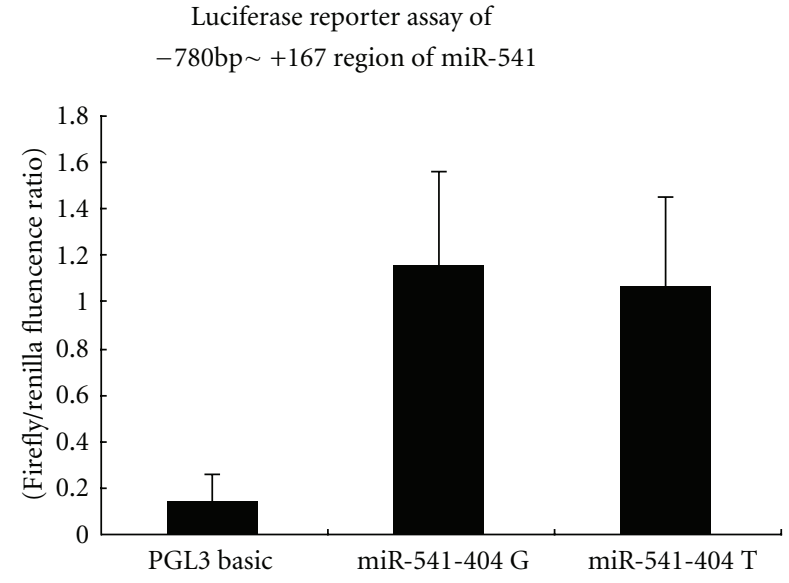

FIGURE 3: Luciferase reporter assay of $-780 \sim+187$ region of miR541. In contrast to PGL3 BASIC control vector, the constructed plasmid containing $-780 \mathrm{bp} \sim+167$ regions had promoter activity, indicating a putative promoter of miR-541 in this region. However, there is no significant difference in promoter activity between wildtype and $-404 \mathrm{G} \rightarrow \mathrm{T}$ mutation construct. $P<0.05$ compared with PGL3 BASIC control.

a relative low incidence of type 1 diabetes, it is hardly to significantly increase sample size in a single center, so a further multicenter analysis may be necessary to validate its clinical significance.

-404 located within putative promoter of pre-miR541 identified by luciferase reporter assay. Current study shows $\mathrm{G} \rightarrow \mathrm{T}$ variant has no effects on promoter activity in luciferase report assay. By RNAfold prediction, $-404 \mathrm{G} \rightarrow \mathrm{T}$ variant leads to a significant secondary structure alteration of pri-miR-541, which may possibly influence its processing and maturation.

If the -404 SNP affects transcription or function of miR541 and this miRNA in turn may modulate target genes like neurogenin3, it would be desirable to include measurements related to mRNA or protein levels for this or other pertinent genes that may be affected by the 404 GT SNP variant. However, miR-541 is reported to be expressed in pancreas and contribute to pancreas development and regeneration [18]; it is generally impossible to get tissue samples from patient, while study from peripheral blood would be of little value compared with study in pancreas and target organ. Further in vitro study with cell line and animal model would be our next plan, to validate the biologic value of miR541 and its -404 SNP. Interestingly, recent study shows that dysregulation of miR-541 in skin contributes to diabetic wound healing in mice model [20], and miR-541 in neuron contributes to neurite outgrowth in rat model [21], so an expression profile in blood and available target tissue such as skin and nerve in human are desirable.

\section{Authors' Contribution}

These authors contribute equally to this work. 
TABLe 3: Comparison of genotype and allele frequency of mir-541 -404 G $\rightarrow$ T identified by RFLP between type 1 diabetes children and control groups.

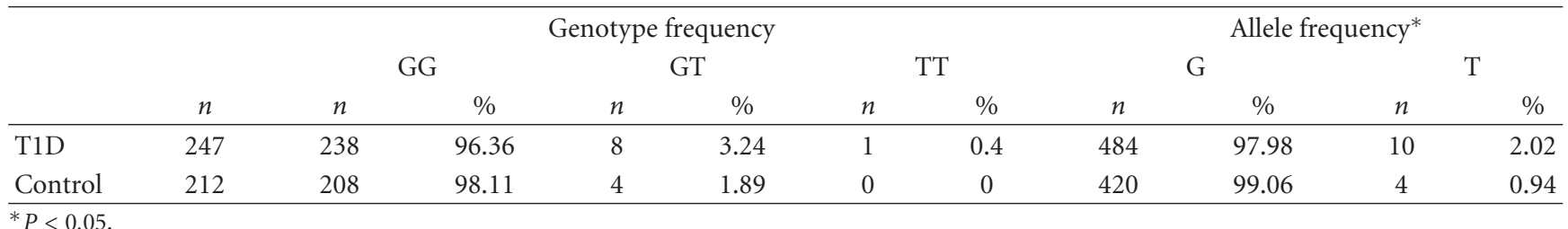

TABLE 4: No significant correlation was found between clinical parameter and allele of mir-541 -404 G $\rightarrow$ T in type 1 diabetes children.

\begin{tabular}{lcccccccc}
\hline Allele & $n$ & Sex male/female & Average age (year) & Average weight $(\mathrm{kg})$ & $\begin{array}{c}\text { C-peptide } \\
0^{\prime}\end{array}$ & $\begin{array}{c}\text { C-peptide } \\
120^{\prime}\end{array}$ & $\begin{array}{c}\text { HbAC } \\
\%\end{array}$ & $\begin{array}{c}\text { Ketoacidosis } \\
\%\end{array}$ \\
\hline $\mathrm{G}$ & 238 & $124 / 114$ & $7.49 \pm 4.04$ & $23.92 \pm 11.18$ & $0.17 \pm 0.16$ & $0.53 \pm 0.65$ & 12.19 & $78 / 238$ \\
$\mathrm{~T}$ & 9 & $4 / 5$ & $7.43 \pm 4.84$ & $22.23 \pm 10.86$ & $0.16 \pm 0.12$ & $0.32 \pm 0.19$ & 12.37 & $4 / 9$ \\
\hline
\end{tabular}

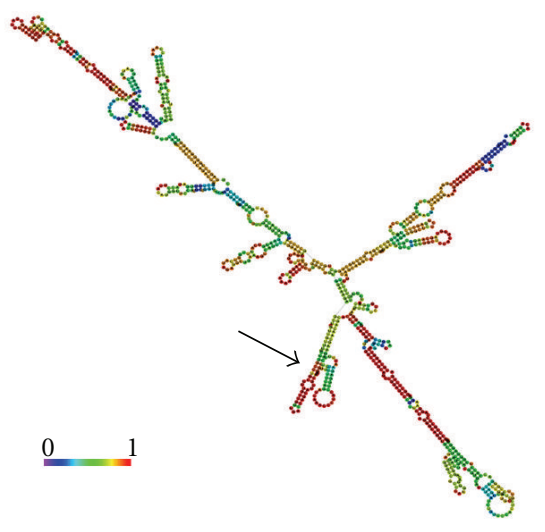

(a) Wild type miR-541 secondary structure

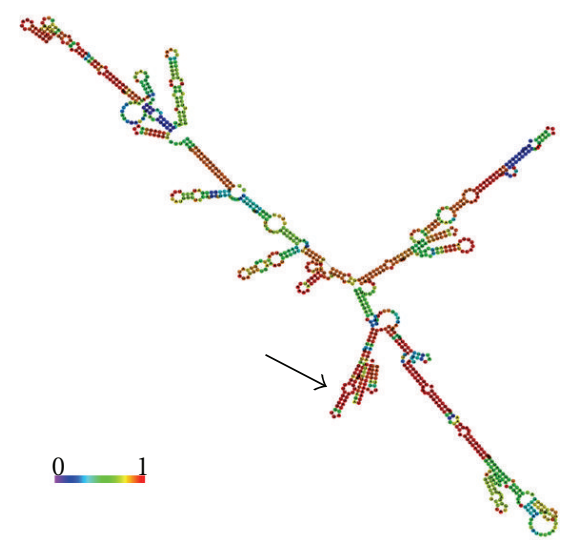

(b) Mutated - $404 \mathrm{G} \rightarrow \mathrm{T}$ secondary structure

FIGURE 4: Alteration in the genetic sequence alters the secondary structure of the miR-541 precursor. The RNA secondary structure predicted by RNAfold web server indicated that a change in the secondary structure of miR-541 precursor may alter the base pair match of its precursor root region. Black arrows indicate the change in the sequence and secondary structure. The most stable secondary structure was selected on the basis of minimum free energy (MFE).

\section{Conflict of Interests}

The authors declare no conflict of interests.

\section{Acknowledgments}

This work was supported by a Science Development Grants 08NMUM048 from Nanjing Medical University and Nature Science Grant no. 30901627 and no. 230486 from National Nature Science Foundation of China.

\section{References}

[1] G. Thomson, W. P. Robinson, M. K. Kuhner et al., "Genetic heterogeneity, modes of inheritance, and risk estimates for a joint study of caucasians with insulin-dependent diabetes mellitus," American Journal of Human Genetics, vol. 43, no. 6, pp. 799-816, 1988.

[2] C. E. Taplin and J. M. Barker, "Autoantibodies in type 1 diabetes," Autoimmunity, vol. 41, no. 1, pp. 11-18, 2008.
[3] A. I. Tarasov, H. J. Welters, S. Senkel et al., "A Kir6.2 mutation causing neonatal diabetes impairs electrical activity and insulin secretion from INS-1 $\beta$-cells," Diabetes, vol. 55, no. 11 , pp. 3075-3082, 2006.

[4] A. Esquela-Kerscher and F. J. Slack, "Oncomirs-microRNAs with a role in cancer," Nature Reviews Cancer, vol. 6, no. 4, pp. 259-269, 2006.

[5] M. N. Poy, L. Eliasson, J. Krutzfeldt et al., "A pancreatic isletspecific microRNA regulates insulin secretion," Nature, vol. 432, no. 7014, pp. 226-230, 2004.

[6] B. R. Gauthier and C. B. Wollheim, "MicroRNAs: ribo-regulators of glucose homeostasis," Nature Medicine, vol. 12, no. 1, pp. 36-38, 2006.

[7] P. Skewes-Cox, Y. Kosaka, M. T. McManus, B. D. Harfe, M. S. German, and F. C. Lynn, "MicroRNA expression is required for pancreatic islet cell genesis in the mouse," Diabetes, vol. 56, no. 12, pp. 2938-2945, 2007.

[8] M. V. Joglekar, V. M. Joglekar, and A. A. Hardikar, "Expression of islet-specific microRNAs during human pancreatic development," Gene Expression Patterns, vol. 9, no. 2, pp. 109-113, 2009. 
[9] A. He, L. Zhu, N. Gupta, Y. Chang, and F. Fang, "Overexpression of micro ribonucleic acid 29, highly up-regulated in diabetic rats, leads to insulin resistance in 3T3-L1 adipocytes," Molecular Endocrinology, vol. 21, no. 11, pp. 2785-2794, 2007.

[10] A. A. Teleman and S. M. Cohen, "Drosophila lacking microRNA miR-278 are defective in energy homeostasis," Genes and Development, vol. 20, pp. 417-422, 2006.

[11] K. M. Pauley and E. K. L. Chan, "MicroRNAs and their emerging roles in immunology," Annals of the New York Academy of Sciences, vol. 1143, pp. 226-239, 2008.

[12] C. H. Bang-Berthelsen, L. Pedersen, T. Fløyel, P. H. Hagedorn, T. Gylvin, and F. Pociot, "Independent component and pathway-based analysis of miRNA-regulated gene expression in a model of type 1 diabetes," BMC Genomics, vol. 12, article 97, 2011.

[13] G. A. Calin, M. Ferracin, A. Cimmino et al., "A microRNA signature associated with prognosis and progression in chronic lymphocytic leukemia," New England Journal of Medicine, vol. 353, no. 17, pp. 1793-1801, 2005.

[14] J. F. Abelson, K. Y. Kwan, B. J. O’Roak et al., "Sequence variants in SLITRK1 are associated with Tourette's syndrome," Science, vol. 310, no. 5746, pp. 317-320, 2005.

[15] M. A. Saunders, H. Liang, and W. H. Li, "Human polymorphism at microRNAs and microRNA target sites," Proceedings of the National Academy of Sciences of the United States of America, vol. 104, no. 9, pp. 3300-3305, 2007.

[16] K. Chen and N. Rajewsky, "Natural selection on human microRNA binding sites inferred from SNP data," Nature Genetics, vol. 38, no. 12, pp. 1452-1456, 2006.

[17] L. Zhou, H. He, J. X. Mi, C. Li, B. Lee, and Q. S. Mi, "MicroRNA genes," Annals of the New York Academy of Sciences, vol. 1150, pp. 72-75, 2008.

[18] M. V. Joglekar, V. S. Parekh, and A. A. Hardikar, "New pancreas from old: microregulators of pancreas regeneration," Trends in Endocrinology and Metabolism, vol. 18, no. 10, pp. 393-400, 2007.

[19] M. V. Joglekar, V. S. Parekh, S. Mehta, R. R. Bhonde, and A. A. Hardikar, "MicroRNA profiling of developing and regenerating pancreas reveal post-transcriptional regulation of neurogenin3," Developmental Biology, vol. 311, no. 2, pp. 603 $612,2007$.

[20] R. Madhyastha, H. Madhyastha, Y. Nakajima, S. Omura, and M. Maruyama, "MicroRNA signature in diabetic wound healing: promotive role of miR-21 in fibroblast migration," International Wound Journal, vol. 9, no. 4, pp. 355-361, 2012.

[21] J. Zhang, J. Zhang, L.-H. Liu et al., "Effects of miR-541 on neurite outgrowth during neuronal differentiation," Cell Biochemistry and Function, vol. 29, no. 4, pp. 279-286, 2011. 


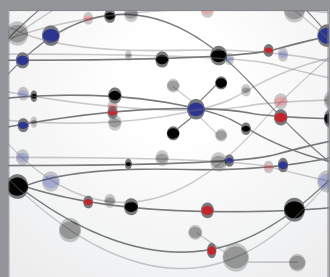

The Scientific World Journal
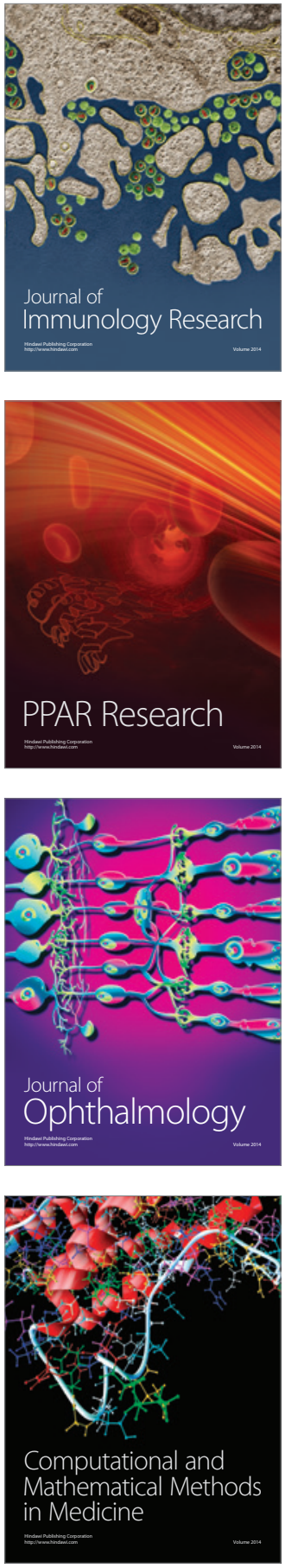

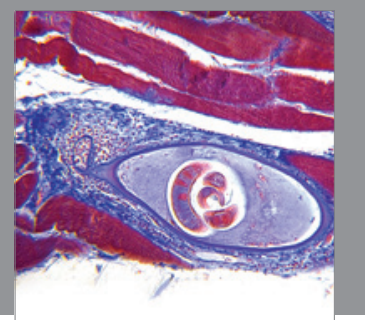

Gastroenterology

Research and Practice
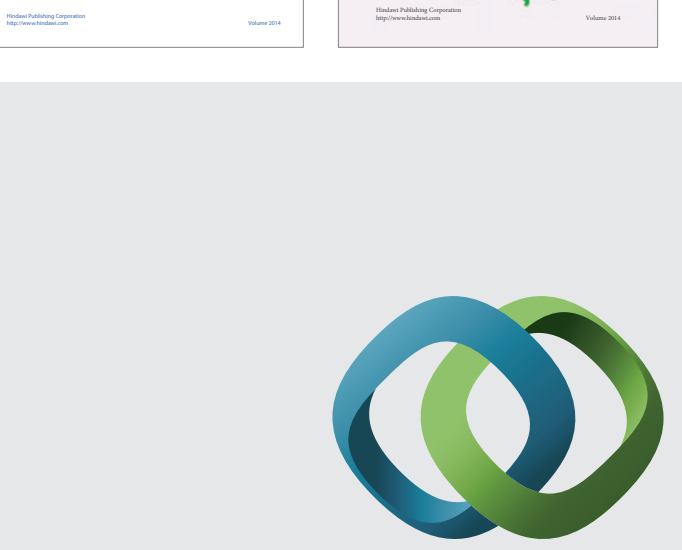

\section{Hindawi}

Submit your manuscripts at

http://www.hindawi.com
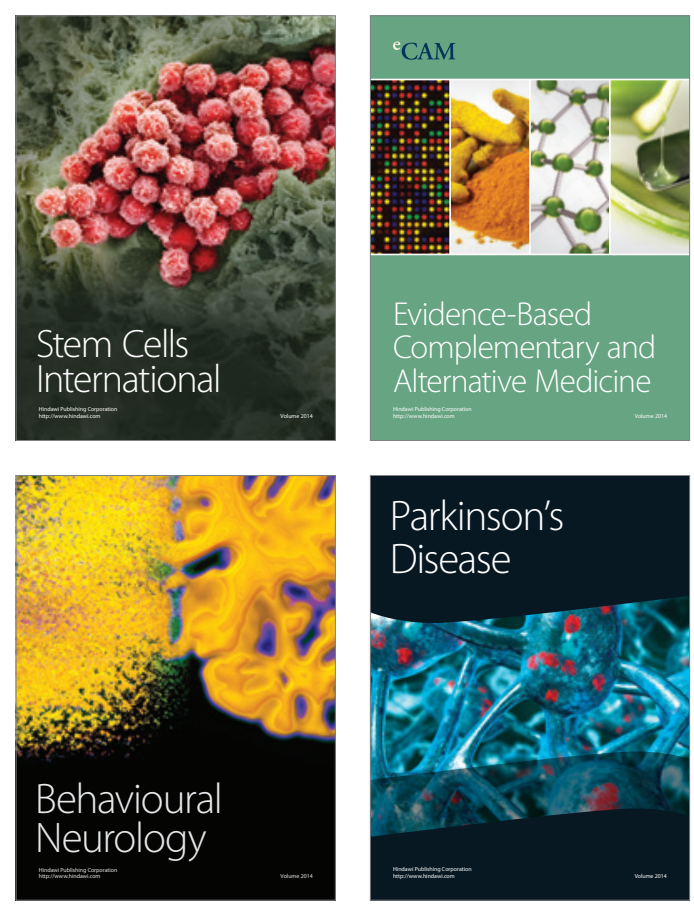

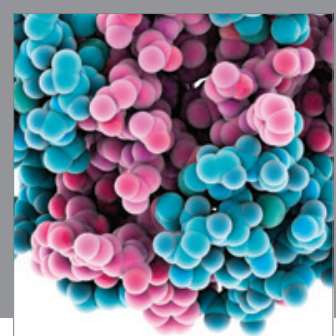

Journal of
Diabetes Research

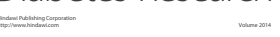

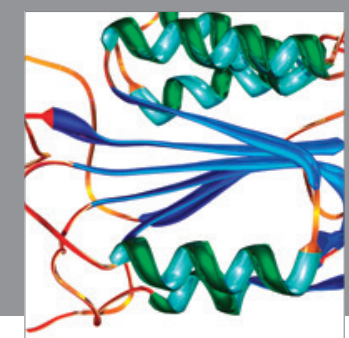

Disease Markers
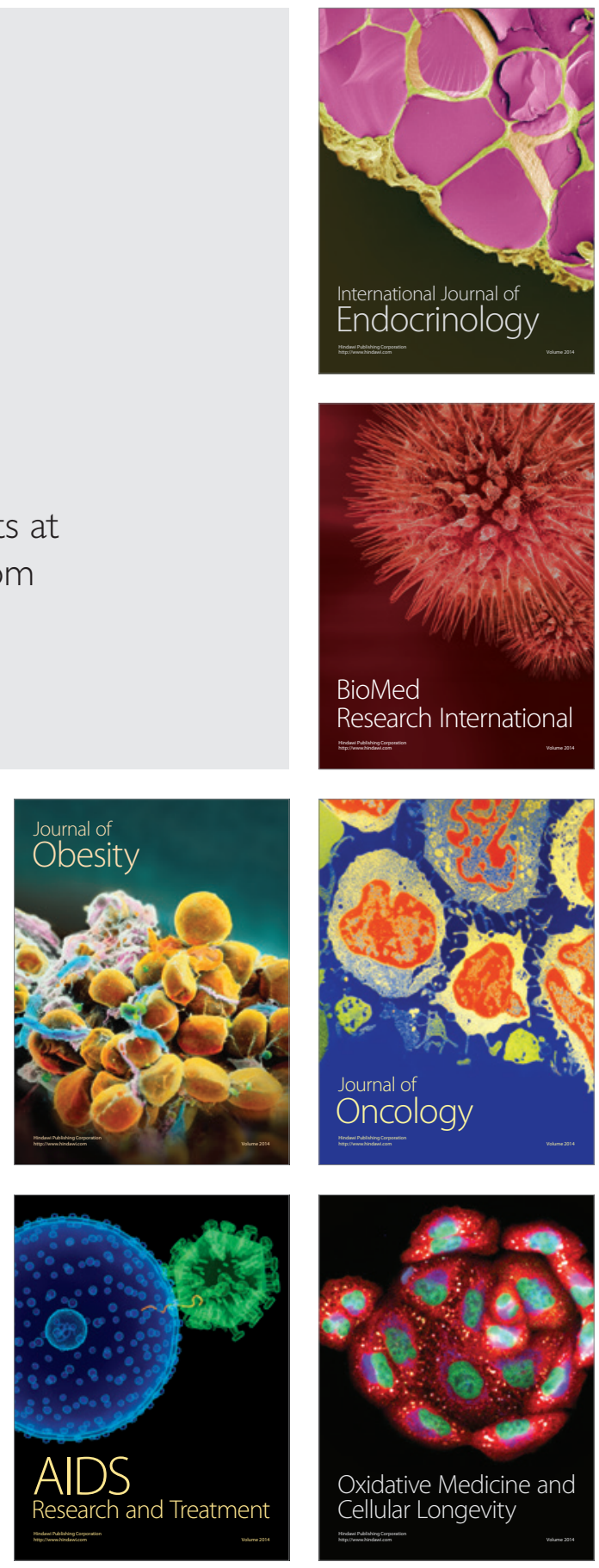